\title{
Model Penyelesaian Sengketa Wanprestasi Kredit Mikro pada Bank Kredit Kecamatan
}

\author{
Setia Cahyaning Fuati ${ }^{*}$, Septi Indrawati ${ }^{2}$ \\ 1,2 Universitas Muhammadiyah Purworejo, Purworejo, Indonesia \\ *email: setyacahyaningfuati236@gmail.com
}

DOI: https://doi.org/10.37729/amnesti.v2i2.653

\begin{tabular}{|c|c|}
\hline & : Jul \\
\hline \multirow{7}{*}{$\begin{array}{l}\text { Kata kunci : } \\
\text { Usaha Mikro, } \\
\text { Kredit Mikro, } \\
\text { Penyelesaian } \\
\text { Sengketa } \\
\text { Wanprestasi }\end{array}$} & ABSTRAK \\
\hline & \multirow{22}{*}{$\begin{array}{l}\text { Usaha Mikro merupakan salah satu penompang ekonomi } \\
\text { masyarakat. Perkembangan Usaha Mikro akan berdampak positif } \\
\text { terhadap pertumbuhan ekonomi. Pencapaian suatu keberhasilan } \\
\text { dalam usaha yaitu dengan adanya dana yang cukup, tetapi kurang } \\
\text { permodalan menjadi persoalan yang umum terjadi di lingkup } \\
\text { usaha. Upaya kredit merupakan salah satu bentuk memperoleh } \\
\text { dana. Kredit Mikro diperuntukan bagi kalangan pemilik usaha } \\
\text { mikro agar memperoleh dana untuk mengembangkan usahanya. } \\
\text { Ketidaklancaran debitur dalam pembayaran dapat memicu } \\
\text { persoalan yang dikatakan sebagai wanprestasi. Wanprestasi } \\
\text { dikatakan juga sebagai kelalaian seorang debitur dalam memenuhi } \\
\text { kewajibannya sebagaimana mestinya. Penelitian ini bertujuan } \\
\text { untuk menganalisis prosedur pengajuan kredit mikro dan model } \\
\text { penyelesaian wanprestasi di Bank Kredit Kecamatan (BKK). } \\
\text { Metode yang digunakan dalam penelitian ini adalah metode } \\
\text { penelitian hukum yuridis normatif. Penelitian ini dilakukan di BKK } \\
\text { Cabang Kemiri, kabupaten Purworejo. Hasil penelitian } \\
\text { menyimpulkan bahwa pengajuan kredit mikro hanya diberikan } \\
\text { kepada calon debitur yang berdomisili di wilayah kecamatan } \\
\text { Kemiri serta memiliki usaha di wilayah tersebut. Pemberian kredit } \\
\text { mikro ini lebih kedalam usaha mikro ranah perdagangan secara } \\
\text { langsung atau offline. Pada pengajuan kredit mikro ini hanya }\end{array}$} \\
\hline & \\
\hline & \\
\hline & \\
\hline & \\
\hline & \\
\hline & \\
\hline & \\
\hline & \\
\hline & \\
\hline & \\
\hline & \\
\hline & \\
\hline & \\
\hline & \\
\hline & \\
\hline & \\
\hline & \\
\hline & \\
\hline & \\
\hline & \\
\hline & \\
\hline
\end{tabular}




\begin{tabular}{|c|c|}
\hline & $\begin{array}{l}\text { diberikan maksimal Rp } 25.000 .000 \text { dengan jangka waktu maksimal } \\
5 \text { tahun. Penyelesaian wanprestasi pada BKK Cabang Kemiri } \\
\text { Kabupaten Purworejo dengan metode klarifikasi awal via telepon } \\
\text { sebelum berlanjut kunjungan kreditur secara langsung ketempat } \\
\text { usaha yang dijalani debitur dan penagihan langsung kerumah } \\
\text { serta pemberian surat peringatan perihal tagihan sebelum diakhiri } \\
\text { dengan penghapusan kredit tapi tidak dengan penghapusan } \\
\text { tanggungan pihak debitur tersebut terhadap pihak BKK Cabang } \\
\text { Kemiri. }\end{array}$ \\
\hline & ABSTRACT \\
\hline $\begin{array}{l}\text { Keywords : } \\
\text { Micro Business, } \\
\text { Micro Credit, } \\
\text { Default Dispute } \\
\text { Resolution }\end{array}$ & $\begin{array}{l}\text { Micro-enterprises are one of the pillars of the community's economy. The } \\
\text { development of Micro Enterprises will have a positive impact on economic } \\
\text { growth. The achievement of business success, namely with sufficient } \\
\text { funds, but lack of capital is a common problem in the scope of business. } \\
\text { Credit efforts are one form of obtaining funds. Micro Credit is intended for } \\
\text { micro-business owners in order to obtain funds to develop their business. } \\
\text { The debtor's failure to make payments can trigger a problem which is } \\
\text { known as a default. Default is also said to be the negligence of a debtor in } \\
\text { fulfilling his obligations properly. This study analyses the procedure for } \\
\text { applying for micro-credit and the model to settle defaults at the District } \\
\text { Credit Bank (BKK). The method used in this study is a normative juridical } \\
\text { legal research method. This research was conducted at BKK Kemiri } \\
\text { Branch, Purworejo district. The study results concluded that the } \\
\text { application for micro credit is only given to prospective debtors who are } \\
\text { domiciled in the Kemiri sub-district and have a business in that area. The } \\
\text { provision of micro-credit is more about micro-enterprises in the realm of } \\
\text { direct or offline trading. In this microcredit application, a maximum of } \\
\text { IDR 25,000,000 is only given with a maximum period of } 5 \text { years. } \\
\text { Settlement of default at the BKK Kemiri Branch, Purworejo Regency with } \\
\text { the initial clarification method via telephone before continuing the } \\
\text { creditor's visit directly to the place of business undertaken by the debtor } \\
\text { and direct billing at home as well as giving a warning letter regarding the } \\
\text { bill before ending with the abolition of credit but not by eliminating the } \\
\text { debtor's dependents to the other party. BKK Kemiri Branch. }\end{array}$ \\
\hline
\end{tabular}

\section{PENDAHULUAN}

Definisi Usaha Mikro menurut Undang - Undang Nomor 20 Tahun 2008 tentang Tentang Usaha Mikro Kecil dan Menengah adalah usaha produktif milik orang perorangan dan atau badan usaha perorangan yang memenuhi 
kriteria. Menurut pasal 6 ayat (1) Kriteria pemilik usaha mikro yaitu memiliki aset atau kekayaan bersih hingga 50 juta, tidak termasuk tanah atau bangunan tempat usaha serta omzet penjualan tahunan hingga 300 juta. Perekonomian nasional menurut pasal 33 ayat (4) Undang - Undang Dasar 1945 diselenggarakan berdasarkan atas demokrasi ekonomi dengan prinsip kebersamaan, efisiensi berkeadilan, berkelanjutan, berwawasan lingkungan, kemandirian, serta dengan menjaga keseimbangan kemajuan dan kesatuan ekonomi nasional.

Pencapaian suatu keberhasilan dalam usaha yaitu dengan adanya dana yang cukup. Salah satu sumber alternatif pendanaan yaitu dengan kredit agar dapat melakukan peluasan dan pengembangan usaha (Rahmawati \& Puspasari, 2017). Menurut pasal 1 angka (11) Undang - Undang Nomor 10 Tahun 1998 Tentang Perbankan Kredit adalah penyediaan uang atau tagihan atau yang dapat dipersamakan dengan itu berdasarkan dengan pemberian bunga.

Adanya kredit untuk tingkat menengah kebawah sangat memperuntungkan bagi mereka yang akan melakukan peluang usaha dengan kendala dalam dana. Kredit Mikro adalah pinjaman dalam jumlah kecil untuk kalangan menengah kebawah dengan tujuan mereka dapat berwirausaha dimana yang tidak memiliki pekerjaan tetap, tidak memiliki jaminan, riwayat kredit yang terpercaya serta tidak mampu untuk mendapatkan kredit biasa (Oktafia, 2018). Kredit Mikro merupakan salah satu cara untuk memberi kesempatan bagi setiap orang khusunya rakyat menengah kebawah untuk memiliki kehidupan layak dan terjamin. Sistem dan prosedur pemberian kredit yang baik akan dapat membantu bank dalam pengambilan keputusan pemberian kredit, sehingga dapat mengantisipasi sebab-sebab terjadinya kegagalan kredit.

Tindakan wanprestasi pada kredit biasa yang sering terjadi tidak menutup kemungkinan pada kredit mikro hal wanprestasi juga akan terjadi. Wanprestasi itu sendiri merupakan pelaksanaan kewajiban yang tidak dipenuhi dan ingkar janji atau kelalaian yang dilakukan oleh pihak debitur baik karena tidak melaksanakan apa yang telah diperjanjikan maupun malah melakukan sesuatu yang menurut perjanjian tidak boleh dilakukan (Adati, 2018). Wanprestasi seorang debitur dapat berupa empat macam, yaitu:

1. tidak melakukan sama sekali apa yang disanggupi akan dilakukannya,

2. melaksanakan apa yang dijanjikannya, tetapi tidak sebagaimana dajanjikan,

3. melakukan apa yang dijanjikan tetapi terlambat 
4. melakukan sesuatu yang menurut perjanjian tidak boleh dilakukannya (Aminah \& Darmawijaya, 2015).

Permasalahan kredit yang menimpa dunia perbankan sebagai akibat dari adanya wansprestasi atau keterlambatan dalam pembayaran oleh debitur ditambah dengan banyaknya kredit yang dijamin dengan jaminan kebendaan akan tetapi jaminan tersebut setelah dijual tidak mencukupi untuk memenuhi hutangnya.

\section{METODE PENELITIAN}

Metode penelitian ini adalah penelitian hukum normatif. Penelitian hukum normatif adalah penelitian hukum yang dilakukan dengan cara meneliti bahan pustaka untuk menemukan aturan hukum, prinsip-prinsip hukum maupun doktrin-doktrin hukum guna menjawab permasalahan hukum yang dihadapi (Muhdlor, 2012). Jenis data penelitian dapat dibedakan menjadi bahan hukum primer dan bahan hukum sekunder. Data primer yaitu data yang bersifat autoritatif atau mempunyai otoritas yang merupakan bahan hukum resmi dan mempunyai kekuatan mengikat. Bahan hukum primer dalam penelitian ini terdiri dari

1. Kitab Undang-undang Hukum Perdata, Undang-undang Republik Indonesia Nomor 14 Tahun 1967 Tentang pokok-pokok Perbankan,

2. Undang-undang Republik Indonesia Nomor 10 Tahun 1998 Tentang Perubahan atas Undang-undang Nomor 7 Tahun 1992 Tentang Perbankan,

3. Undang-undang Nomor 20 Tahun 2008 Tentang Usaha Mikro, Kecil dan Menengah, Peraturan Bank Indonesia Nomor 17/12/PBI/2015 Tentang Perubahan atas Peraturan Bank Indonesia Nomor 14/22/PBI/2012 Tentang Pemberian Kredit atau Pembiayaan oleh Bank Umum dan Bantuan Teknis Dalam Rangka Pengembangan Usaha Mikro, Kecil dan Menengah,

4. Peraturan Otoritas Jasa Keuangan Republik Indonesia Nomor 19/POJK.03/2018 tentang Penilaian Kualitas Aset Bank Umum Stariah dan Unit Usaha Syariah BAB III, Pasal 31B , ayat (3).

Data sekunder yaitu semua publikasi tentang hukum yang bukan merupakan dokumen resmi. Publikasi tentang hukum meliputi buku teks, kamus hukum, jurnal hukum dan pendapat hukum. Data sekunder dalam penelitian ini berupa buku Hukum Perdata, buku Perbankan, dan buku Metodologi Penelitian serta Penulisan Karya Ilmiah, makalah dan artikel, meliputi makalah mengenai kredit kususnya kredit mikro dan penyelesaian 
wanprestasi kredit mikro,jurnal Ilmiah, jumlah kredit mikro di BKK Cabang Kemiri. Analisis data dalam penelitian ini menggunakan metode kualitatif. Metode kualitatif yaitu menguraikan bahan hukum dalam bentuk kalimat yang teratur, runtun, logis, tidak tumpang tindih dan efektif. Data dalam penelitian ini disajikan dalam teks naratif yang disusun secara sistematis. Sistematis berarti keseluruhan data yang diperoleh akan dikaitkan dengan pokok permasalahan yang diteliti, yaitu mengenai kredit mikro dan wanprestasi.

\section{HASIL DAN PEMBAHASAN}

BKK merupakan Badan Perkreditan Kecamatan. BKK termasuk kedalam BPR (Suparno \& Wibowo, 2009). BPR atau Badan Perkreditan Rakyat menurut Undang - Undang Nomor 10 Tahun 1998 Tentang Perbankan Bab I, Pasal 1 ayat (4) merupakan bank yang melaksanakan kegiatan usaha secara konvensional atau berdasarkan Prinsip Syariah yang dalam kegiatannya tidak memberikan jasa dalam lalu lintas pembayaran. Fungsi utama perbankan Indonesia adalah sebagai penghimpun dan penyaluran dana masyarakat. Fungsi utama dari bank tersebut sesuai dalam Undang-undang pasal 3 Nomor 10 Tahun 1998 tentang perbankan.

Salah satu hal terpenting dalam pengajuan kredit yaitu adanya perjanjian kredit antara dua belah pihak terkait dimana perjanjian tersebut dilakukan oleh pihak kreditur selaku pemberi pinjaman dan pihak debitur selaku peminjam atau penerima pinjaman (D. R. Hidayat, 2018). Dalam perjanjian sudah ditentukan waktu pembayaran sesuai kedua belah pihak, maka dari itu seorang pemberi pinjaman atau kreditur tidak dapat mengambil atau menarik pinjaman sebelum waktu yang telah disepakati dalam perjanjian tersebut (N. Hidayat, 2014).

Hal ini sesuai dengan Pasal 1759. Kredit Mikro di BKK Cabang Kemiri merupakan pinjaman yang diberikan dengan jumlah maksimal 25.000.000. Pinjaman ini diberikan kepada pelaku usaha untuk wilayah Kecamatan Kemiri saja. Hal ini dilakukan untuk mendukung laju perekonomian pelaku usaha mikro khususnya di wilayah kecamatan Kemiri. Prosedur pengajuan Kredit Mikro di BKK Cabang Kemiri adalah :

1. Pengisian formulir

2. Surat keterangan dari pihak desa

3. Usaha online harus ada bukti penyetokan barang atau homestore

4. Maksimal pengajuan kredit mikro Rp 25.000.000 
5. Sebelum adanya persetujuan kredit, pihak kreditur berhak melakukan survey terlebih dahulu ke pihak calon debitur

Wanprestasi berarti kealpaan, kelalaian, tidak menepati janji, tidak memenuhi kontrak. Jadi, wanprestasi adalah suatu keadaan dalam mana seorang debitur (berutang) tidak melaksanakan prestasi yang diwajibkan dalam suatu kontrak, yang dapat timbul karena kesengajaan atau kelalaian debitur itu sendiri dan adanya keadaan memaksa (overmacht) (Dsalimunthe, 2017). Wanprestasi sebagaimana yang dimaksud diatur dalam Peraturan Otoritas Jasa Keuangan Republik Indonesia Nomor 19/POJK.O3/2018, yaitu, nasabah dinyatakan wanprestasi sebagaimana dimaksud pada ayat (2) dalam hal (Trimulyo, 2017):

1. Terjadi tunggakan pokok dan/atau margin/bagi hasil/ujrah dan/atau tagihan lain selama 90 (sembilan puluh) hari meskipun aset produktif belum jatuh tempo.

2. Tidak diterimanya pembayaran pokok dan/atau margin/bagi hasil/ujrah dan/atau tagihan lain pada saat aset produktif jatuh tempo; atau

3. Menurut Peraturan Otoritas Jasa Keuangan Republik Indonesia Nomor 19/POJK.03/2018 tentang Penilaian Kualitas Aset Bank Umum Stariah dan Unit Usaha Syariah BAB III, Pasal 31B, ayat (3) tidak dipenuhinya persyaratan lain selain pembayaran pokok dan/atau margin/bagi hasil/ujrah yang dapat mengakibatkan terjadi wanprestasi.

Terjadinya wanprestasi pada kredit mikro di BKK Cabang Kemiri ini merupakan wanprestasi dalam bentuk debitur keliru berprestasi. Wanprestasi dalam perjanjian kredit Mikro di BKK Cabang Kemiri merupakan suatu kenyataan yang disebabkan oleh berberapa faktor antara lain yaitu karena gagal usaha, usaha kurang lancar,dan persoalan internal. Berdasarkan kredit Mikro yang ada di BKK Cabang Kemiri terkait bunga kredit mikro yakni 9\% per tahun. Sistem pendendaan apabila ada keterlambatan maupun kelalaian dalam pembayaran angsuran yang sudah ditetapkan makan terkena denda $1 \%$ dari angsuran untuk setiap harinya.

\section{KESIMPULAN}

Prosedur pengajuan kredit khususnya kredit mikro pada BKK Cabang Kemiri Kabupaten Purworejo sudah sesuai dengan ketentuan pengajuan kredit di lingkup perbankan di Indonesia. Pada pengajuan kredit mikro ini hanya diberikan maksimal Rp 25.000.000 dengan jangka waktu maksimal 5 tahun. 
Penyelesaian wanprestasi pada BKK Cabang Kemiri Kabupaten Purworejo diakhiri dengan penghapusan kredit tapi tidak dengan penghapusan tanggungan pihak debitur tersebut terhadap pihak BKK Cabang Kemiri.

\section{DAFTAR PUSTAKA}

Adati, M. A. (2018). Wanprestasi Dalam Perjanjian Yang Dapat Di Pidana Menurut Pasal 378 Kitab Undang-Undang Hukum Pidana. Lex Privatum, $6(4), 5-15$.

Aminah, \& Darmawijaya, A. (2015). Analysis Procedure For Credit in Efforts to Minimize Non Performing Loans on PT. Bank Lampung. Jurnal Akuntansi Dan Keuangan, 6(2), 25-46. https://doi.org/10.36448/jak.v6i2.574

Dsalimunthe, D. (2017). Akibat Hukum Wanprestasi Dalam Perspektif Kitab Undang-Undang Hukum Perdata (BW). Jurnal Al-Maqasid, 3(1), 12-29.

Hidayat, D. R. (2018). Perlindungan Hukum Bagi Kreditur dengan Jaminan Atas Objek Jaminan Hak Tanggungan Yang Sama. Jurnal Ilmu Hukum, 14(27), 1-16. https://doi.org/10.5281/zenodo.1188346.1

Hidayat, N. (2014). Tanggung Jawab Penanggung dalam Perjanjian Kredit. Jurnal Ilmu Hukum Legal Opinion, 2(4), 1-9.

Oktafia, R. (2018). Percepatan Pertumbuhan Usaha Mikro, Kecil Dan Menengah (Umkm) Melalui Perkuatan Lembaga Keuangan Mikro Syariah (Lkms) Di Jawa Timur. Badan Pusat Statistik Indonesia, 3(1), h. 85-92. https://www.bps.go.id

Rahmawati, T., \& Puspasari, O. R. (2017). Implementasi Sak Etap Dan Kualitas Laporan Keuangan Umkm Terkait Akses Modal Perbankan. Jurnal Kajian Akuntansi, 1(1), 49-62. https://doi.org/10.33603/jka.v1i1.510

Suparno, \& Wibowo, E. (2009). Analisis Tiingkat Kesehatan Bank Sebelum dan Setelah Merger pada PD.BPR BKK Karangmalang Kabupaten Sragen. Jurnal Manajemen Sumberdaya Manusia, 3(1), 25-32.

Trimulyo, S. (2017). Pelaksanaan Perjanjian Pembiayaan Konsumen Dan Implikasi Wanprestasi Terhadap Objek Jaminan (Studi Kasus Di Pt. Oto Multiartha Cabang Mataram) the Implementations of Financial Consumer Agreements and Its Implication of Breach of Contract Against the Objec. Jurnal IUS Kajian Hukum Dan Keadilan, 5(1), 88-109. 